\title{
Lovastatin Acid
}

National Cancer Institute

\section{Source}

National Cancer Institute. Lovastatin Acid. NCI Thesaurus. Code C77442.

The active, acid form of lovastatin. In the body lovastatin is hydrolysed to its betahydroxy acid active form. 